\title{
ENEM: O LEVIATÃ DA EDUCAÇÃO BRASILEIRA?
}

ENEM: THE LEVIATHAN OF BRAZILIAN EDUCATION?

Marcello Vieira LASNEAUX ${ }^{1}$

ISSUE DOI: $10.21207 / 1983.4225 .519$

\section{RESUMO}

A instauração de um Estado-avaliador tem se mostrado uma tendência aparentemente sem retorno. Qual o propósito da avaliação de larga escala? O ENEM é uma avaliação de larga escala, mas esse é o propósito atual do ENEM? Além disso, o ENEM, vem sendo indicado pela imprensa à população em geral, como referência de qualidade das escolas. A inquietude é: o exame por si só é capaz de avaliar as instituições de ensino? Esses exames foram criados para isso? Esses exames estão vivendo uma espécie de "crise de identidade", uma crise política-educacional? Precisamos discutir mais amplamente o papel já descaracterizado do ENEM e unir forças para não assistir um retrocesso aos domínios da escuridão que assistimos em outras épocas.

Palavras-chave: Avaliação, ENEM, Gestão educacional.

\section{ABSTRACT}

The establishment of the rule evaluator has been an apparent trend of no return. What is the purpose of evaluating a large scale? The ENEM is a large-scale assessment but this is the current purpose of the ENEM? In addition, the ENEM, has been mentioned by the media to the general public, as quality reference schools. The concern is: the test itself is able to assess the educational institutions? These tests were created for this? These tests are living a kind of "identity crisis", a political-educational crisis? We need to discuss more fully the role already mischaracterized the ENEM and join forces to not watch a throwback to the realms of darkness have seen at other times.

\footnotetext{
${ }^{1}$ Doutorando em Educação pela Universidade de Brasília (UnB), Brasília/DF. Mestre em Bioética, pela Faculdade de Saúde, Cátedra UNESCO, da Universidade de Brasília. Especialista em Gestão Escolar. Especializando em Neurociência. Bacharel e licenciado em Ciências Biológicas pela Universidade de Brasília (UnB). Especialista em Genética Humana. Currículo Lattes: http://lattes.cnpq.br/8578358447017085. Contato: lasneaux@gmail.com
} 
Keywords: Social Security, Public Policies, Fundamental Rights.

\section{INTRODUÇÃO}

O presente artigo tem como escopo demonstrar a premente necessidade de garantir ao cidadão uma maior efetividade dos direitos sociais através das políticas públicas ligadas à seguridade social. A realidade brasileira é marcada por agudas desigualdades sociais, grande parte da população enfrenta dificuldades para obter uma condição de vida digna.

A história recente da educação brasileira representa uma série de mudanças de paradigmas. Dentre essas mudanças, a instauração de um Estado-avaliador tem se mostrado uma tendência aparentemente sem retorno. Essa necessidade parece caminhar juntamente com todas as recentes mudanças pelas quais o país vem atravessando, tendo como marcos legais, no que ser refere à questão da educação, a constituição de 1988 e a Lei de Diretrizes e Base de 1996.

A avaliação é um dos temas mais discutidos hoje em educação. O foco do debate foi por muito tempo a avaliação da aprendizagem. Atualmente, além da avaliação do aluno, é importante igualmente avaliar o desempenho docente, dos cursos, das instituições e do sistema educacional.

Avaliar é preciso. Parece imperativo que a escola avalie e seja avaliada. Quando se fala em avaliar pensa-se logo em avaliação de rendimento, aplicação de provas e testes nos alunos. Para a maioria das pessoas, trata-se apenas disso: notas em uma folha de papel. Reforçados pelas experiências pessoais e pelo seio midiático, avaliar parece apenas medir conhecimento. No entanto, o campo da avaliação educacional é extenso e complexo e está além do meramente medir saberes: seu papel deve ser muito mais o de auxiliar o construir. Está desmembrado em micro e macroanálises, em uma série de meandros e subáreas. Há igualmente uma diversidade no campo teórico o que só vem aumentar a complexidade de toda essa seara (GATTI, 2002). A avaliação educacional pode ser dividida em três tipos: a avaliação de aprendizagem, a avaliação de sistemas e a avaliação institucional (SOUSA. 2010).

A avaliação institucional procura aferir a instituição, avaliação esta que deve, a princípio, se posicionar entre as duas outras, servindo de 
seus elementos para o entendimento focal da instituição (figura 1). Muitas instituições, especialmente de nível superior, vêm se utilizando dessa modalidade de avaliação para tomada de decisões sobre os rumos do ensino. A avaliação institucional deve estar associada com a da mudança institucional, deve estar inserida no conceito de uma escola reflexiva (FREITAS et al., 2009).

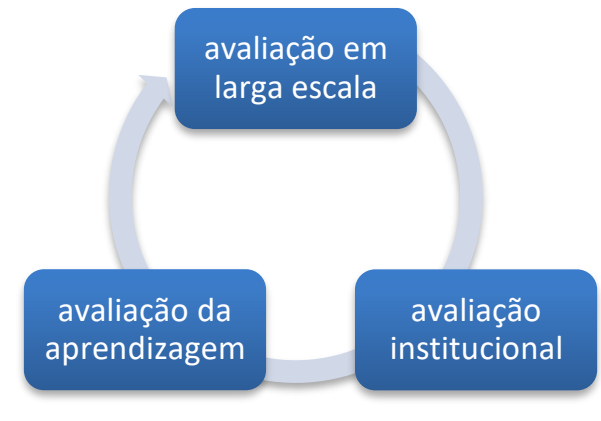

Figura 1. Relação entre as diversas formas de avaliação educacional. (modificado de FREITAS et al., 2009, p. 10)

O segmento de avaliação em larga escala está em expansão e consolidação no cenário brasileiro, atingindo a educação básica e a educação superior. A proposta não é a de apenas aferição de resultados, mas traz consigo a indução do aprimoramento da qualidade dos sistemas e das instituições de ensino. Na esteira desse modelo de aferição, surgiram exames nacionais como o SAEB (1990), ENEM (1997) e ENCCEJA (2002). Aliado a essa política nacional, a administração do INEP. Entretanto vive um momento chave em que se estabelece uma indecisão entre uma prática verdadeiramente consolidada ou uma ferramenta para questões de interesse. Diversas questões outras devem ser levadas em consideração tais como: "necessidade, pertinência, validade, legitimidade, natureza, fundamentos, referências, finalidades, funções, usos, origem, modalidades, métodos, instrumentos, operacionalização, possibilidades e limitações dessa prática." (FREITAS, 2007). A produção e a difusão de dados têm sido facilitadas pelas contingências resultantes da informatização dos sistemas e pela velocidade dos veículos de comunicação, especialmente com a popularização da internet.

Sobre a estratégia, pode-se afirmar que esse tipo de avaliação:

a) emergiu da articulação da pesquisa e do planejamento educacional; 
b) firmou-se por todo um arcabouço de normas implantadas juridicamente além de possuir sustentáculos políticosadministrativos;

c) fomentou e subsidiou a ação regulatória (no sentido de intervenção) do Estado;

d) realizou ações educativas materializada por diversas medidas pedagógicas.

A ação reguladora do Estado está pautada em "diretrizes, políticas, estratégias, instrumentos, mecanismos, medidas e ações de gestores" inscritos em toda a esfera educacional (FREITAS, 2007). Essa ação deve estar ancorada nas aferições que servem como base para medidas decisórias e ações pertinentes. A avaliação deve oferecer elementos elucidativos do pensar-agir criticamente nos âmbitos pedagógico e político.

Avaliar é emitir juízo de valor, mas densamente apoiado em dados coletados com todo suporte prévio para geração da pesquisa. Nesse sentido, o Estado como proponente e executor deve estar assentado com seus propósitos e azeitado com seus pares para buscar exequibilidade e resultância.

Esse trabalho tem o objetivo claro de resgatar a história da avaliação em larga escala no Brasil e apontar a gênese dos principais exames nacionais nesse sentido mostrando a vocação com que nasceram e sinalizar possíveis mudanças de rumo, possíveis falhas em relação aos seus princípios e buscar em alguns coordenadores de escolas avaliadas a opinião sobre o que de fato tem sido essas formas de pesquisas para suas instituições. Nessa tentativa, será feita uma revisão sustentada em documentos oficiais de criação, a legislação constitucional e outras, para apresentar claramente para que caminho percorreu a avaliação nesse país. Também serão importantes diversas iniciativas pioneiras em diversas regiões e momentos com destaque para o Edurural, praticado na região Nordeste do Brasil, no início até meados da década de 1980. Todas essas informações são preciosas para o entendimento do estágio atual dos fatos. A história é uma perspectiva atuante no presente e um balizador para possíveis mudanças futuras.

\section{O ENEM}


Com a portaria n. 438, de 28 de maio de 1998, o então ministro Paulo Renato Souza cria o ENEM (Exame Nacional do Ensino Médio):

\footnotetext{
Artigo $1^{\circ}$ - Instituir o Exame Nacional do Ensino Médio - ENEM, como procedimento de avaliação do desempenho do aluno, tendo por objetivos:

I - conferir ao cidadão parâmetro para auto-avaliação, com vistas à continuidade de sua formação e à sua inserção no mercado de trabalho;

II - criar referência nacional para os egressos de qualquer das modalidades do ensino médio;

III - fornecer subsídios às diferentes modalidades de acesso à educação superior;

IV - constituir-se em modalidade de acesso a cursos profissionalizantes pós-médio. (BRASIL, 1998)
}

A proposta do exame é de que o exame "avaliará as competências e as habilidades desenvolvidas pelos examinandos ao longo do ensino fundamental e médio, imprescindíveis à vida acadêmica, ao mundo do trabalho e ao exercício da cidadania, tendo como base a matriz de competências especialmente definida para o exame" (BRASIL, 1998)

O ENEM surge como outra proposta de avaliação de larga escala, com foco distinto do SAEB, sendo restrito ao ensino médio e cuja "participação no ENEM é voluntária, circunscrita aos egressos do ensino médio em qualquer um de seus cursos, independentemente de quando o concluíram, e aos concluintes da última série do ensino médio, também em qualquer uma das suas modalidades, podendo o interessado participar dos exames quantas vezes considerar de sua conveniência." O exame possui uma taxa de inscrição sendo isentos:

I - concluintes do ensino médio em instituição pública;

II - aos carentes concluintes do ensino médio da rede particular de ensino, mediante declaração do dirigente da instituição;

III - aos concluintes do ensino médio na modalidade de educação de jovens e adultos - concluído entre abril de 2000 até abril de 2001;

IV - aos egressos desse nível de ensino, mediante declaração de carência firmada por si próprio, quando capaz, pelos pais ou responsáveis. (BRASIL, 1998).

\section{O responsável pelo planejamento e operacionalização do ENEM é o INEP.}


Nesse objetivo, existe uma explícita referência do poder, que se confirmaria mais tarde, do ENEM adentrar na fisiologia do acesso ao nível superior, concomitante ou não com o já conhecido e questionado vestibular.

"Constituir-se em modalidade de acesso a cursos profissionalizantes pós-médio". Sinaliza que o mesmo pode acontecer com o acesso a essa outra modalidade de ensino.

Com a portaria n. 110, de 14 de dezembro de 2002, o ENEM ganha novos objetivos.

Art. $2^{\circ}$ Constituem objetivos do ENEM/2003:

I - oferecer uma referência para que cada cidadão possa proceder à sua autoavaliação com vistas às suas escolhas futuras, tanto em relação ao mercado de trabalho quanto em relação à continuidade de estudos;

II - estruturar uma avaliação da educação básica que sirva como modalidade alternativa ou complementar aos processos de seleção nos diferentes setores do mercado de trabalho;

III - estruturar uma avaliação da educação básica que sirva como modalidade alternativa ou complementar aos exames de acesso aos cursos profissionalizantes pós-médios e ao Ensino Superior.

Com a mudança da redação dos objetivos, torna-se mais claro o direcionamento no sentido do ENEM ser um exame de transição para outros níveis. As novidades foram a sugestão de que o ENEM pudesse ser usado para outros fins que não o do acesso às faculdades para, especulouse na época, para assumir cargos públicos, por exemplo, o que vai de encontro com a nova redação do objetivo II.

Em 2006, com a portaria n. 7, o artigo $2^{\circ}$. sofre nova mudança, voltando a ter quatro incisos sendo o IV com a redação; "possibilitar a participação e criar condições de acesso a programas governamentais".

Em 2009, os objetivos saltam para sete, conforme descrito abaixo:

Art. $2^{\circ}$ Constituem objetivos do Enem:

I - oferecer uma referência para que cada cidadão possa proceder à sua auto-avaliação com vistas às suas escolhas futuras, tanto em relação ao mundo do trabalho quanto em relação à continuidade de estudos;

II - estruturar uma avaliação ao final da educação básica que sirva como modalidade alternativa ou complementar aos processos de seleção nos diferentes setores do mundo do trabalho; 
III - estruturar uma avaliação ao final da educação básica que sirva como modalidade alternativa ou complementar aos exames de acesso aos cursos profissionalizantes, pós-médios e à Educação Superior;

IV - possibilitar a participação e criar condições de acesso a programas governamentais;

V - promover a certificação de jovens e adultos no nível de conclusão do ensino médio nos termos do artigo 38 , §§ 1o- e 2oda Lei no- 9.394/96 - Lei das Diretrizes e Bases da Educação Nacional (LDB);

VI - promover avaliação do desempenho acadêmico das escolas de ensino médio, de forma que cada unidade escolar receba o resultado global;

VII - promover avaliação do desempenho acadêmico dos estudantes ingressantes nas Instituições de Educação Superior.

Com a portaria n.109, oficializa-se, em outras palavras, a divulgação dos rankings entre as escolas sob a roupagem de que "cada unidade" receberá "o resultado global". Na verdade, o resultado estará disponível para qualquer um acessar no sítio do INEP.

Em 2011, é publicada a portaria n. 16. O ENEM sofre novas mudanças. No seu primeiro artigo afirma: "O interessado em obter certificação no nível de conclusão do ensino médio ou declaração de proficiência com base no Exame Nacional de Ensino Médio-ENEM, deverá atender aos seguintes requisitos:

I - possuir 18 (dezoito) anos completos até a data de realização da primeira prova do ENEM;

II - ter atingido o mínimo de 400 pontos em cada uma das áreas de conhecimento do ENEM;

III - ter atingido o mínimo de 500 pontos na redação.

Dessa forma, o ENEM passa ter mais uma função: a de certificar qualquer cidadão, maior de idade, que queira ter o diploma de ensino médio. Para isso, estipula um desempenho mínimo: "Para a área de linguagens, códigos e suas tecnologias, o interessado deverá obter o mínimo de 400 pontos na prova objetiva e, adicionalmente, o mínimo de 500 pontos na prova de redação."

Surge uma evidência de seu uso como ferramenta para avaliação institucional apresentado no seu segundo artigo: "O INEP disponibilizará às Secretarias de Educação dos Estados e do Distrito Federal e aos Institutos Federais de Educação, Ciência e Tecnologia as notas e os dados cadastrais dos interessados." Mas parece que não para uma espécie de 
avaliação externa e sim para ter acesso à informação de quem poderá ser certificado. Observe a redação abaixo:

\footnotetext{
Art. $3^{\circ}$ Compete às Secretarias de Educação dos Estados e aos Institutos Federais de Educação, Ciência e Tecnologia, definir os procedimentos complementares para certificação no nível de conclusão do ensino médio com base nas notas do ENEM.

$\S 1^{\circ}$ As Secretarias de Educação dos Estados e os Institutos Federais de Educação, Ciência e Tecnologia poderão aproveitar as notas de uma ou mais áreas de conhecimento avaliadas no ENEM, de acordo com o interesse e a solicitação de certificação no nível de conclusão do ensino médio ou declaração de proficiência.

$\S 2^{\circ}$ É de responsabilidade das Secretarias de Educação dos Estados e dos Institutos Federais de Educação, Ciência e Tecnologia emitir os certificados de conclusão ou declaração de proficiência, quando solicitado pelo interessado.

Art. $4^{\circ} \mathrm{A}$ certificação pelo ENEM destina-se, prioritariamente, às pessoas que não concluíram o Ensino Médio em idade apropriada, inclusive às pessoas privadas de liberdade e que estão fora do sistema escolar regular.

Art. $5^{\circ} \mathrm{A}$ certificação pelo ENEM não pressupõe a frequência em escola pública para efeito de concessão de benefícios de programas federais.

Art. $6^{\circ}$ Fica aprovado, na forma do anexo a esta Portaria, o modelo para certificação de proficiência equivalente à conclusão do Ensino Médio para os fins da certificação da educação de jovens e adultos com base no Exame Nacional do Ensino Médio - ENEM.
}

\section{O ENEM, A IMPRENSA E A COMUNIDADE ESCOLAR}

O processo de avaliação vive sempre um elenco de críticas pertinentes ao sistema e sua construção e seus objetivos: qual é a finalidade última da avaliação educacional? Quais têm sido as efetivas contribuições das avaliações para a melhoria da qualidade educacional? Quem são os beneficiários de tais processos? (DALBEN, 2010). A essas questões acrescentam-se outras como: as escolas têm interesse no processo? Elas admitem a importância de serem avaliadas? Elas conhecem todos os exames e o motivo de suas existências? Como as avaliações de larga escala têm sido abarcadas pelas instituições? Como o Estado reage à questão da leitura que a imprensa faz da qualidade do ensino das instituições tendo apenas com base a divulgação dos resultados dos exames de larga escala, como o ENEM?

O presente trabalho surge de uma inquietação que há tempos vem-se percebendo: a mudança de um Estado-educador para um Estado- 
avaliador e Estado-regulador, como a própria presidente do INEP em 1997, declarou em sessão no Seminário Internacional de Avaliação do mesmo ano (FREITAS, 2007). Além disso, dos exames de larga escala, particularmente o ENEM, vem sendo adotado pela imprensa e extensivamente à população em geral, como referência de qualidade das escolas. A inquietude é: o exame por si só é capaz de avaliar as instituições de ensino? Esses exames foram criados para isso? As escolas estão "interessadas" em participar dessa modalidade de avaliação? Qual o propósito do ENEM? Qual o propósito da avaliação de larga escala? Esses exames estão vivendo uma espécie de "crise de identidade"?

Veja por exemplo o teor da reportagem publicada no jornal Folha de São Paulo, em 31 de março de 2012, no caderno Cotidiano. A manchete diz "Nota das melhores escolas paulistas despenca em exame". Continua: "Entre 349 colégios mais bem colocados no Idesp em 2010, 252 tiveram nota menor no ano passado e caíram no ranking" (MONTEIRO et al., 2012). Mais além na mesma reportagem: "Além de avaliar a performance dos alunos, índice serve para pagar bônus a professores da rede”. A única foto da reportagem é da escola estadual Amelia Kerr Nogueira, que teve a pior nota em avaliação da quinta série. Tem-se aqui uma síntese dos problemas dos exames que apresentam como vocação a avaliação institucional. Primeiro, o destaque que se dá ao "ranqueamento". Segundo a ausência do poder público como interlocutor das possíveis justificativas para o resultado. Terceiro, a indexação financeira associada ao resultado, para premiação dos professores. Quarto, a condenação da deficiência imputada, na reportagem, pelos pais e pelos alunos à falta de docentes. A seriedade dos fatos e divergência do uso das ferramentas é origem de muitas críticas. A própria Folha de $S$. Paulo publicou na seção "Tendências/Debates" em 26 de março, o argumento crítico sobre a corrida da premiação aos professores com base em resultados, comparando a educação a um programa de metas da iniciativa privada, ressaltando que tal comportamento pode acentuar ainda mais as desigualdades. A autora salienta que em países como China, Canadá e Finlândia, os melhores colocados são estimulados a cooperar com seus pares com menor desempenho, um encorajamento que está resumido no título do texto: "Os melhores professores para as piores escolas (SETUBAL, 2012). Todas essas visões caucionam a ideia de que a avaliação de larga escola tem subvertido seus propósitos.

$\mathrm{Na}$ esteira da divulgação dos resultados das escolas, a imprensa noticia largamente em suas primeiras páginas. A população, refém dos 
grandes veículos de informação, assume a postura da redação realizada pelos jornalistas. Assim, a ideia de "as 10 melhores" e "as 10 piores" é uma simplificação assustadora para quem de fato está preparado para entender os dados obtidos. As escolas bem colocadas, por sua vez, usam desses resultados e até das próprias reportagens para apontarem como as "melhores" da cidade, do estado e do país. Esse expediente é particularmente utilizado pelas escolas da iniciativa privada que passam a assumir os resultados com olhar próprio que querem para estampar outdoors nas suas campanhas de captação de novos alunos ou aproveitamse da propaganda pronta já apresentada sob forma de artigo e reportagem nos jornais, internet, rádio e tv. A população aponta as melhores escolas como aquelas que vão melhor nos exames de maior divulgação. Esse papel era devotado aos vestibulares, mas de forma muito mais empírica uma vez que era sustentada no nome dos alunos mais bem colocados. Como as avaliações governamentais aferem a escola, a comparação se dá mais óbvia e diretamente. $\mathrm{O}$ aumento de proporção e de impacto dos resultados devese também a mudanças de paradigmas mais recentes, legitimados por portarias publicadas na década passada. No caso do ENEM, houve a adesão do programa do PROUNI - para disponibilização de bolsas de estudos - e de diversas universidades ao exame como forma de acesso. Essas decisões aumentaram ainda mais a visibilidade e o interesse no exame que se refletiu em um aumento absurdo na participação por parte do alunado.

\section{OS GESTORES E O ESTADO-AVALIADOR}

A falta de estudiosos no assunto no país se reflete na carência de publicações, no entendimento dos dados e na resposta do Estado frente à sua própria proposta de examinar para compreender seu sistema. Esse cenário tem mudado conforme percebe-se no aumento de seu alcance. Esse dilema no campo das ações também é motivo de preocupação sendo que os resultados tem sido processados de forma questionável e o Estado vem tendo dificuldade de dar uma resposta nítida às comunidades escolares e à população em geral. Em contrapartida, a velocidade da veiculação dos dados permeia distorções e simplificações do seu entendimento.

Cabe finalmente questionar junto aos gestores escolares se entendem o papel que a avaliação externa tem na conjuntura de sua escola. É importante ouvir todos os segmentos da comunidade para perceber o que 
está por trás desses exames. O presente trabalho propõe identificar a percepção de alguns gestores a respeito do assunto. Há uma importância sincera na percepção dos alunos, pais, funcionários e professores sobre toda essa questão, até para que o Estado-avaliador também seja avaliado, tornando-se o processo uma via de duas mãos. O interessante é que, na análise dos documentos, essa espécie de avaliação da avaliação parece estar fora dos propósitos imaginados pelos redatores das ideias. $\mathrm{O}$ momento político oferece essa possibilidade, visto que não vivemos Estados autoritários como na década de 1930, 1940 e durante o período militar. O meio acadêmico deveria ser o algoz ou contraponto das iniciativas governamentais, municiando obviamente de informações para a criticidade dos modelos, para seu aperfeiçoamento e não para sua extinção. Avaliar é preciso, mas o processo deve ser consistente, deve ser participativo, compreensível por todos e não deturpado, unilateral e blindado à crítica. $\mathrm{O}$ presente trabalho procura uma centelha para acender a discussão em torno de todo o cenário atual, uma busca real de elementos para questionar os rumos das propostas e suas interpretações por diversos atores sociais, importantes na construção do contexto escolar e, acima de tudo, para a melhoria do sistema e da prestação do serviço, até para não permitir que existam arbitrariedades decisórias que podem significar gastos públicos desnecessários, evasão discente, insatisfação dos profissionais da educação, dúvidas da comunidade sobre qualidade da escola e irresponsabilidade por parte dos gestores.

\section{O ENEM TEM UM PAPEL DE DEMOCRATIZAÇÃO DO ACESSO?}

A possibilidade de democratizar o acesso dos jovens às universidades brasileiras em um exame com base em uma abordagem diferente e com questões mais contextualizadas e menos providas de "decorebas" sempre foi um discurso pronto para alavancar a adesão ao exame. Mas será que é verdade?

Analisemos o caso da Universidade de Brasília. Atualmente, entre outras formas de acesso, existem três grandes concursos para a entrada na universidade: o PAS (programa de avaliação seriada - seleção 
feita com três provas, uma a cada final de ano do ensino médio), vestibular e Sistema de Seleção Unificada (SISU).

Veja o comparativo divulgado pela Universidade no dia 06/12/2015, em sessão para professores convidados, na qual estive presente:

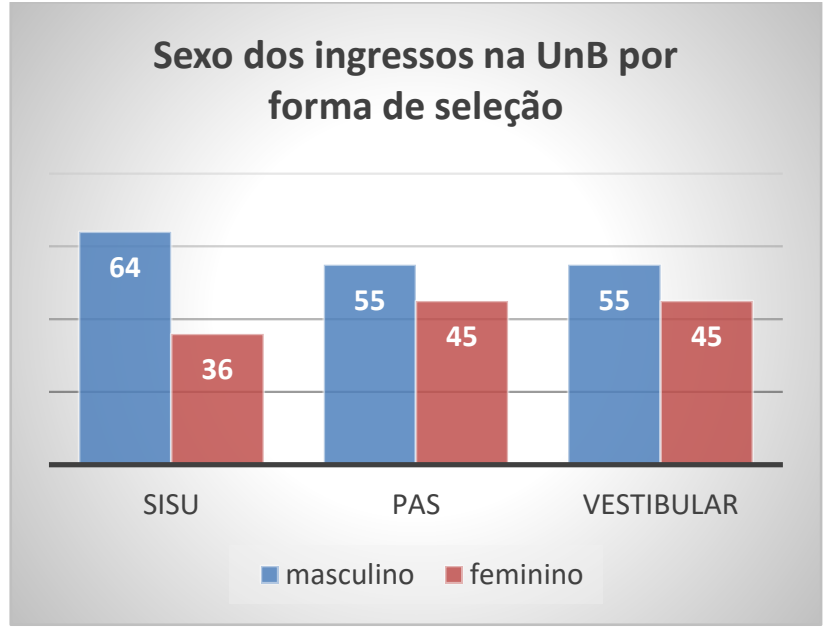

Observa-se que o SISU está gerando uma universidade muito mais masculina, ao contrário do exame do PAS e do vestibular. Assim, estamos democratizando a educação no país?

Observe ainda o dado sobre a idade de entrada do aluno, segundo a forma de seleção.

\section{MÉDIA DE IDADE (EM ANOS)}

- SISU vestibular $\square$ PAS

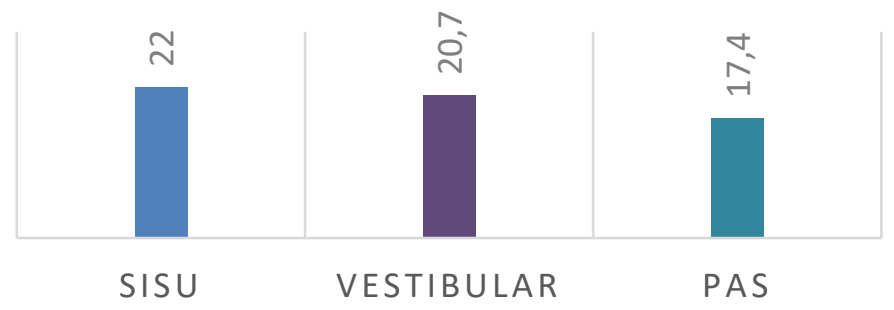




\section{CONSIDERAÇÕES FINAIS}

"É necessário levar o inquérito às práticas educacionais. Procurar medir a educação, não somente em seus aspectos externos, mas em seus processos, métodos e práticas, conteúdo e resultados reais obtidos." Essas palavras são de Anísio Teixeira (1967). Entretanto, há um arcabouço extenso de questões a serem dissecadas em torno da tríade "medidaavaliação-informação" (FREITAS, 2007) no que tange a avaliação de larga escala no Brasil.

O conceito de qualidade de ensino é variável com o tempo e com sua história. Dessa forma, avaliar para se chegar a uma meta é uma tarefa que se interpõe de inúmeras dificuldades teóricas e práticas. A evolução da pertinência do ENEM ensaiado nesse trabalho demonstra bem o quanto há uma crise política-educacional a ser resolvida.

A contribuição das avaliações para quase todos os pensadores consiste em permitir mudança, uma retroalimentação para reconstruir, buscar a melhoria. Como percebe-se pela evolução dos objetivos do ENEM há um claro olhar para o aluno e não para o ensino. O ENEM serve para uma autocrítica de um aluno que recém saiu da "placenta" do ensino médio, sem que aparentemente isso sirva de lição para ninguém, nem para o próprio aluno que nada tem a mais a fazer uma vez que já se desligou da escola. A outra função, que reside no acesso ao nível superior também se encerra em si sem fomentar a discussão e a contrapartida para a construção dos futuros egressos do ensino médio.

A imprensa necessita de buscar balizas mais justas e plurais para a divulgação e a apresentação da informação. Designados como o "quarto poder", o discurso dos jornalistas deve contar com a diversidade de opiniões e o devido cuidado ideológico de sua utilização. Outro elemento importante, é a cautela linguística para oferecer aos receptores da informação, no caso, a comunidade em geral, informação sem ruído. A simplificação dos dados e interpretações mnemônicas promovem uma silhueta que apenas tangencia a verdade da situação.

O ENEM é o leviatã da educação brasileiro? Estaria o ENEM sendo uma forma de poder do Estado, e um risco de "totalitarismo" educacional? A divulgação dos rankings pode cavar mais o fosso entre as escolas "boas" e as "ruins"? E o ENEM? Ele corre o risco de se tornar (apenas) o novo vestibular? 
Precisamos discutir mais amplamente o papel já descaracterizado do ENEM e unir forças para não assistir um retrocesso aos domínios da escuridão que assistimos em outras épocas.

\section{REFERÊNCIAS BIBLIOGRÁFICAS}

BRASIL. Portaria n.438, de 28 de maio de 1998. Institui o Exame Nacional do Ensino Médio. Disponível em: <www.crmariocovas.sp.gov.br〉. Acessado em: 21 abr. 2012.

DALBEN, A. Avaliação Institucional na Escola de Educação Básica: uma aproximação orientada pelos princípios da participação, Disponível em: 〈http://www.periodicos.rc.biblioteca.unesp.br/>. Acessado em: 01 abr. 2012.

FREITAS, D. A avaliação da educação básica no Brasil, 1. ed. Campinas: Autores Associados, 2007. $224 \mathrm{p}$.

FREITAS, L. C.; SORDI, M. R. L.; MALAVASI, M. M. S.; FREITAS, H. C. L., Avaliação educacional - caminhando pela contramão. 1. ed. Petrópolis: Ed. Vozes, 2009. 86 p.

GATTI, B. A., Avaliação Educacional no Brasil: pontuando um a história de ações, EccoS Rev. Cient., UNINOVE: São Paulo: (n.1, v. 4): 17 - 41, 2002.

INEP, Relatório pedagógicos. Disponível em: < http://portal.inep.gov.br/web/enem/relatoriospedagogicos >. Acessado em: 28 abr. 2012.

MONTEIRO, A.; TAKAHASHI, F.; BEDINELLI, T., Notas das melhores escolas paulistas despenca em exame. Folha de S. Paulo, São Paulo, 31 mar. 2012, Caderno Cotidiano, p.4.

SETUBAL, M. A., Os melhores professores para as piores escolas. Folha de S. Paulo, São Paulo, 26 mar. 2012, Caderno Opinião, p.3.

SOUSA, S. M., Qualidade da educação, gestão democrática e avaliação - Avaliação institucional: autoavaliação e avaliação externa, 2010. Disponível em:

http://periodicos.unisantos.br/index.php/pesquiseduca/article/view/20/pdf >. Acessado em: 01 abr. 2012. 